\title{
Relationship between age and blastocyst chromosomal ploidy analyzed by noninvasive preimplantation genetic testing for aneuploidies (niPGT-A)
}

Laura D. Vagnini ${ }^{1}$, Claudia G. Petersen ${ }^{1,2}$, Adriana Renzi ${ }^{1}$, Felipe Dieamant ${ }^{2}$, João B.A. Oliveira ${ }^{2}$, Antonio H. Oliani $^{3}$, Maria C.T. Canas $^{1}$, Raul Nakano ${ }^{4}$, Carlos G. Almodin ${ }^{5}$, Condesmar Marcondes 6 , Alvaro Ceschin7, Adelino Amaral8, Jonathas B. Soares ${ }^{9}$, Joaquim Lopes $^{10}$, Antonio C. Franco ${ }^{11}$, Jose G. Franco Jr. ${ }^{1,2}$

\author{
${ }^{1}$ Paulista Center for Diagnosis Research and Training, Ribeirao Preto - CPDP, Brazil. \\ ${ }^{2}$ Centre for Human Reproduction Prof Franco Jr, Ribeirao Preto, Brazil. \\ 3São José do Rio Preto School of Medicine FAMERP, Sao Jose do Rio Preto, Brazil. \\ ${ }^{4}$ Ferticlin Human Fertility Clinic, Sao Paulo, Brazil. \\ 5 Materbaby, Maringa, Brazil. \\ ${ }^{6}$ Santista Nucleus of Human Reproduction, Santos, Brazil. \\ 7Feliccita Fertility Institute, Curitiba, Brazil. \\ ${ }^{8}$ Genesis Human Reproduction Assistance Center, Brasília, Brazil. \\ ${ }^{9}$ Alpha Project-Alliance of Assisted Fertilization Laboratories, São Paulo, Brazil. \\ ${ }^{10}$ Cenafert, Salvador, Brazil. \\ ${ }^{11}$ Embryolife, São José dos Campos, Brazil
}

\begin{abstract}
Objective: To assess the relationship between human blastocyst chromosomal ploidy established by niPGT-A and increasing age.
\end{abstract}

Methods: This is a prospective multicenter study carried out by ten assisted reproduction centers after their embryologists acquired training and validated their results with the previous use of niPGT-A. A total of 94 couples with indication for niPGT-A due to increase maternal age, male factor, repeated implantation failures, recurrent abortion or because they requested niPGT-A were included in this study. The couples had no karyotype abnormalities. After ICSI, the embryos were cultured until blastocyst stage using one or two step culture systems, single or sequential media respectively, at $37^{\circ} \mathrm{C}$ in an atmosphere of $6-7 \%$ $\mathrm{CO} 2$ and $5-20 \%$ O2 incubators. On day 3 , we re-evaluated cleavage embryos to complete cumulus cells removal. The embryos were then cultured in individual well, with $20 \mu \mathrm{l}$ of medium under oil until they reached blastocyst stage. The blastocysts were vitrified and stored in liquid nitrogen. After that, the spent blastocyst culture medium $(20 \mu \mathrm{l})$ was transferred to a PCR tube and sent for analysis in the genetic laboratory, where it was stored at $-80^{\circ} \mathrm{C}$ until sequencing. A total of 243 samples of spent blastocyst culture medium were collected on the 5th/6th day. Cellfree DNA secreted on culture medium was amplified using NICS Sample Preparation Kit (Yikon Genomics), based on the MALBAC technology. After whole genome amplification, the DNA was measured using a Qubit 2.0 fluorometer and subjected to next generation sequencing (NGS) using Illumina MiSeq ${ }^{\circledR}$ platform. The data were analyzed using the ChromGo $^{\circledR}$ software (Yikon Genomics).

Results: The mean age of the patients was $38 \pm 4.08$ years with an interval of 20-44 years. The euploid was diagnosed in $36.4 \%(80 / 220)$ of cases, aneuploidy in $31.3 \%(69 / 220)$, and mosaicism in $32.3 \%$ (71/220; with $\geq 60 \%$ aneuploidy) of blastocysts. Mosaic values ranged from $29.8 \%$ to $33.8 \%$ in different age groups. Individually, the most frequent chromosomal abnormality was XXY (Klinefelter Syndrome) occurring in 18 cases, followed by chromosome 21 (trisomy/monosomy) in 8 cases. The niPGT-A data showed a $\geq 60 \%$ incidence of aneuploid cells in all cases of chromosomal mosaicism $(n=71)$.
Conclusion: A high degree of mosaicism with aneuploidy cells was detected, and some hypotheses were suggested for this data (niPGT-A sensitivity in detecting the self-correction of chromosomal abnormalities phenomenon). However, it did not vary remarkably with age. On the other hand, euploidy levels had a negative correlation with age and aneuploidy levels had a positive relationship. This is the first report in the literature to relate chromosomal ploidy in blastocysts using niPGT-A and increasing patient age.

Keywords: age, mosaicism, niPGT-A, PGT-A, free DNA, preimplantation genetic diagnosis

\section{INTRODUCTION}

More than 20 years after the use of invasive preimplantation genetic testing to diagnosis embryonic aneuploidy (iPGT-A), several problems associated to the efficiency of this technique are still being discussed (mosaicism, loss of embryos by biopsy, low clinical effectiveness, etc) and most of them remain without an adequate solution (Homer, 2019; Gleicher et al., 2018; Gleicher et al., 2020).

Embryonic chromosomal mosaicism is a phenomenon characterized by two or more genetically distinct cell lineages. Today, we still do not fully comprehend its impact on implantation and in the developmental potential of embryo (Spinella et al., 2018).

In recent studies, several authors have demonstrated that mosaic blastocysts hold the potential to implant and result in the birth of healthy babies without chromosomal changes (Greco et al. 2015; Fragouli et al., 2017; Munné et al., 2017a; Spinella et al., 2018).

From a clinical point of view, the iPGT-a effectiveness as a method for selecting euploidy embryos remains a matter of controversy. The literature points to a lack of scientific evidence (few randomized quality studies) to assess its efficiency when confronted, versus the simple evaluation of embryonic morphology, a parameter traditionally used since the beginning of "in vitro" fertilization in the embryonic selection process (Orvieto, 2016; Munné et al., 2019).

If these criticisms were not enough, the presence of chromosomal mosaicism in human blastocysts creates significant levels of false positive results, and worst, it causes a real possibility of discarding healthy embryos. Thus, the clinical 
application of iPGT-A has an imponderable potential for error in the selection process of choosing blastocysts (Greco et al., 2015; Munné et al., 2017a; Spinella et al., 2018).

Munné et al. (2019) described that all laboratories participating in a randomized study evaluated samples for mosaicism, but the standard protocol for reporting mosaicism differs between the clinical laboratories: five laboratories reported mosaicism when observed; four laboratories designated samples as "no aneuploidy detected" or "abnormal" depending on whether the found level of mosaicism was below or above, respectively, the set chromosome-specific thresholds. A low-level (10-20\% abnormal cells) mosaic sample would likely be reported as euploidy by all labs, a $20-50 \%$ mosaic may be reported as mosaic by the former labs and as euploidy by the latter labs, a 50$80 \%$ mosaic may also be reported as mosaic by the former labs and as aneuploidy by the latter labs, and a high-level (80-90\% abnormal cells) mosaic would likely be reported as aneuploidy by all labs.

Then, the iPGT-A efficiency in the selection process for viable blastocysts could be compromised by mosaicism identification criteria, since its frequency could vary in the modern next generation sequencing (NGS / genetic testing platform) from $2 \%$ to $50 \%$ (Popovic et al., 2020) or up to $80 \%$ (Munné et al., 2017a).

$\mathrm{Xu}$ et al. (2016) recently described a noninvasive chromosomal screening (niPGT-A) by obtaining and sequencing free-DNA dripped by blastocysts in the culture medium (without the need of embryo biopsy) creating a new non-aggressive and elegant perspective to preimplantation genetic diagnosis.

Therefore, our objective was to study the characteristics of mosaicism chromosome of the human blastocyst, assessed by niPGT-A, in relation to increase age, as well as their degree of aneuploidy/euploidy detected by NGS genetic testing platform.

\section{MATERIALS AND METHODS Study design and patients}

This is a prospective study performed in ten assisted reproduction centers, carried out from June 1st (2019) to March 15th (2020) following the rules on Assisted Reproduction of the Federal Medical Board and all couples signed an informed consent form. All centers had their embryologists submitted to a training process and were validated for the use of niPGT-A. A total of 94 couples with indication for niPGT-A due to advanced maternal age, male factor, repeated implantation failures, recurrent abortion or because they requested genetic diagnosis (niPGT-A) were included in this work. The couples had no chromosomal karyotypes abnormalities. A total of 243 samples of spent blastocyst culture media were collected on the 5th/6th day, and sent for laboratorial genetic analysis.

\section{IVF Laboratory: Oocyte denudation, embryo culture}

After one hour of retrieval, all oocytes were denudated using hyaluronidase 40UI, for 2-3 minutes. The corona cells were completely removed using a $150 \mu \mathrm{m}$ stripper to minimize patient contamination and the oocytes were classified according to their level of maturity. ICSI was performed in all MII oocytes. After ICSI, embryos were cultured until blastocyst stage, in single or sequential media, at $37{ }^{\circ} \mathrm{C}$ in an atmosphere containing 6-7\% CO2 and $5-20 \%$ O2.

On Day 3, the cleaved embryos were re-evaluated for the complete removal of cumulus cells by washing them individually for 3 times, to remove any still attached granulosa cells surrounding the embryos. The embryos were transferred to individual wells, with $20 \mu$ l medium in GPS dishware (SP38-010) under oil and cultured until they reach blastocyst stage on 5th/6th day, kept in culture for 48 to 96 hours.

\section{Sample collection and blastocyst vitrification}

At the moment of medium collection, blastocysts were morphologically assessment according to Garden's classification, vitrified and stored in liquid nitrogen. All spent medium from blastocyst, left in each microdroplet of GPS dish was loaded into an identified sterile $0.2 \mathrm{ml}$ PCR tube, containing $5 \mu \mathrm{l}$ lysis buffer, using individually stretched pipette. The PCR tubes were stored at $-20^{\circ} \mathrm{C}$ at least $24 \mathrm{hrs}$ before shipping for genetic evaluation. A sample $(20 \mu \mathrm{l})$ of the medium from one individual well (GPS dish) in which no embryos were cultured was also collected and used as the control. During medium collection, all the procedures were handled under sterile conditions by using flow, mask, cap, gloves and sterile materials.

\section{Whole Genome Amplification and DNA sequencing}

The free DNA secreted into the culture medium by the blastocyst was amplified using NICS Sample Preparation Kit (Yikon Genomics), based on MALBAC technology. After whole genome amplification, the DNA was measured using a Qubit 2.0 fluorometer (Thermo Fisher Scientific) and subjected to NGS using Illumina MiSeq ${ }^{\circledR}$ platform.

\section{Data analysis}

ChromGo (Yikon Genomics) software was used to analyze sequencing data and report chromosomal abnormalities. This software allows the evaluation of entire chromosomes, analysis of the short and long arms of each chromosome, detection of deletion or duplication $>10 \mathrm{Mb}$, in addition to allowing the detection of embryo sex and the presence of mosaicism.

\section{RESULTS}

The mean age of the patients was $38 \pm 4.08$ with an interval of 20-44 years. The average number of eggs collected in MII was $6.8 \pm 3.9$.

The determination of the ploidy levels was carried out in 220 of the 243 samples submitted to the MALBAC technology that had enough concentration and quality of the genomic DNA (integrity and purity). No diagnosis was detected in 23 samples of the 243 for the following reasons: 1. Low DNA concentration $(10 / 243=4.1 \%) ; 2$. Sequencing failure $(12 / 243=5 \%) ; 3$. Contamination of granulosa cells $(1 / 243=0.4 \%)$. Euploidy was diagnosed in $36.4 \%(80 / 220)$ of cases, aneuploidy in 31.3\% (69/220), and mosaicism ( $\geq 60 \%$ aneuploidy) in $32.3 \%$ (71/220) of blastocysts.

Table 1 and Figure 1 show the distribution of chromosomal ploidy by niPGT-A in different age groups: <35 years; $35-37$ years; $38-40$ years, $41-42$ years, $>42$ years. Table 2 analyzes the percentage of mosaicism, their frequency in the chromosomal abnormalities and distribution in

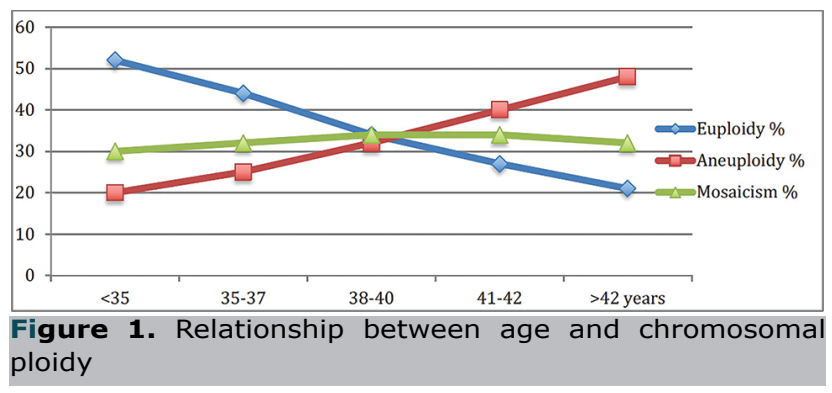


different age groups. Mosaic values ranged from $29.8 \%$ to $33.8 \%$ in different age groups. Individually, the most frequent chromosomal abnormality was XXY (Klinefelter Syndrom) occurring in 18 cases, followed by chromosome 21 in 8 cases. Those defined as 'others' included the remainder autosomal chromosomes. In addition, the relationship between X (119/220) and Y (101/220) chromosomes was $54 \% / 46 \%$, with an SR index of 1.17

\section{DISCUSSION}

The current understanding of the source of cell-free DNA in blastocyst culture media is limited. However, we cannot deny that niPGT-A can detect genomic DNA, not only from the trophectoderm cells but also from the inner cells mass (ICM) of the blastocyst. Although, the precise contribution of each of these cell groups to the final concentration of free DNA is difficult to assess. In addition, it would be worth remembering that iPGT-A determines the genetic status by analyzing a few cells of the trophectoderm, which in essence would give origin to the chorion and the placenta. On the other hand, niPGT-A could also inform the genetic composition of the ICM cells, consequently with genetic information about the future fetus (Taylor et al., 2014).

In 1999, Hardy said that cell death is a widespread feature in the blastocysts of many mammals. Isolated cells of both the ICM and the trophectoderm undergo cell death. These dying cells appear morphologically to be undergoing apoptosis. The role of cell death in development is unknown, but could involve the elimination of abnormal cells, or a lineage of cells with an inappropriate developmental potential. Studies in different organ systems have demonstrated that cell death is regulated by the activity of apoptosis genes. Theoretically, the apoptosis process could be the main source of production of free-DNA collected for niPGT-A execution. The percentage and speed in the elimination of abnormal cells (self correction) can be analyzed with certain ploidy characteristics of embryos. In the same line of thought, Bolton et al. (2016) showed in a mosaic mouse model that both aneuploid and euploid cells from the ICM, as well as from the trophectoderm, undergo apoptosis. In addition, these investigators showed that a higher percentage of cells from ICM became apoptotic compared with trophectoderm cells regardless they were aneuploid $(41.4 \%$ vs. $3.3 \%)$ or euploid $(19.5 \%$ vs. $0.6 \%)$.

Our niPGT-A data (Table 1) showed that the incidence of cases labeled as chromosomal mosaicism $(n=71)$ did not vary significantly in relation to age but it has a high degree of aneuploidy, all cases with values $\geq 60 \%$ of aneuploidy cells. From a scientific point of view, it would always be advisable to describe the threshold level of aneuploidy in the group of mosaic embryos. A simple classification for mosaicism in niPGT-A can be recommended according to which chromosome is involved and the level of aneuploidy: 1)
Lower ( $<30 \%$ aneuploidy cells); moderate $(\geq 30 \%-<50 \%$ aneuploidy cells) and higher ( $\geq 50 \%$ aneuploidy cells) for chromosomes 13, 16, 18 and $21 ; 2$ ) Lower ( $<40 \%$ aneuploidy cells); moderate ( $\geq 40 \%-\leq 60 \%$ aneuploidy cells) and higher ( $>60 \%$ aneuploidy cells) for all other chromosomes. This would greatly facilitate a future process of mosaicism comparative analysis. In addition, it should be mandatory to describe the genetic platform of the test and its respective cut-off for each chromosome analyzed.

However, Kushnir et al. (2018) related no significant differences in ongoing pregnancy or miscarriage rates among mosaic embryo transfers in the iPGT-A at any threshold of aneuploidy. Based on area under the curve (receiver operating curves), the trophectoderm biopsies predicted ongoing pregnancy for euploid, as well as mosaic embry$\mathrm{os}$, in a range of 0.50 to 0.59 and miscarriage in a range from 0.50 to 0.66 . Similarly, Victor et al. (2019a) related that the degree of mosaicism in the iPGT-A should not be used to prioritize mosaic embryos selection, because when analyzing the data using two different cut-offs, low $(20 \%$ $-<50 \%$ ) versus high ( $\geq 50 \%-80 \%)$ degree of mosaicism, the differences in relation to pregnancy outcomes between groups were not statistically significant.

On the other hand, Rubio et al. (2019) related the follow-up data on a subset of patients after single embryo transfer performed according to iPGT-A results and compared the clinical outcome retrospectively according to niPGT-A evaluation. Interestingly, ongoing implantation rates were three times higher when both iPGT-A and niPGT-A were euploid than when euploid iPGT-A was paired with aneuploidy niPGT-A (52.9\% vs. $16.7 \%$, respectively), indicating that embryonic free-DNA (niPGT-A) might open a new avenue for the understanding of embryo ploidy.

Recently, Fang et al. (2019) and Olcha et al. (2020) used niPGT-A with a methodology similar to that used in this study to analyze 170 and 1,480 blastocysts and reported a total percentage of chromosomal mosaicism of $20.5 \%$ and $32.6 \%$, respectively. Unfortunately, the degree of mosaicism was not described, this fact precluded any comparative analysis with our data.

It would not be a simple task to compare the chromosomal mosaicism data by niPGT-A versus those obtained through iPGT-A. Mosaic values in iPGT-A ranged from $2 \%$ to 50\% (Orvieto et al., 2016; Huang et al., 2017; Popovic et al., 2018; Chuang et al. 2018; Tsuiko et al., 2018: Lawrenz et al., 2019; Victor et al., 2019b), even with the use of the NGS platform and relatively similar populations. Munné et al. (2017b) using iPGT-A observed that unlike aneuploidy of meiotic origin, the incidence of chromosomal mosaicism (probably originated by mitotic errors) does not change with advancing age affecting $30 \%$ of embryos in the blastocyst stage. These data are very similar to those found in this study using niPGT-A.

Table 1. Distribution of chromosomal ploidy according to age rate

\begin{tabular}{|c|c|c|c|c|}
\hline & $\begin{array}{c}\text { Spent culture } \\
\text { medium } \\
(\mathbf{n = 2 2 0})\end{array}$ & Euploidy & Aneuploidy & $\begin{array}{c}\text { Mosaicism* } \\
\text { Aneuploidy/Euploidy } \\
(\mathbf{n = 7 1})\end{array}$ \\
\hline <35 years & 47 & $24(51.1 \%)$ & $9(19.1 \%)$ & $14(29.8 \%)$ \\
\hline $\mathbf{3 5 - 3 7}$ years & 32 & $14(43.8 \%)$ & $8(25.0 \%)$ & $10(31.2 \%)$ \\
\hline $\mathbf{3 8 - 4 0}$ years & 77 & $26(33.8 \%)$ & $25(32.4 \%)$ & $26(33.8 \%)$ \\
\hline $\mathbf{4 1 - 4 2}$ years & 45 & $12(26.7 \%)$ & $18(40.0 \%)$ & $15(33.3 \%)$ \\
\hline >42 years & 19 & $4(21.0 \%)$ & $9(47.4 \%)$ & $6(31.6 \%)$ \\
\hline
\end{tabular}


Table 2. Mosaicism and chromosomal abnormalities in different age groups

\begin{tabular}{|c|c|c|c|c|c|}
\hline & $<35$ years & $35-37$ years & $38-40$ years & 41-42 years & $>42$ years \\
\hline $\begin{array}{c}\text { Mosaicism* } \\
(n=71)\end{array}$ & 14 & 10 & 26 & 15 & 6 \\
\hline $\begin{array}{c}\text { Chr } 18 \\
(n=6)\end{array}$ & $\begin{array}{c}2 \\
(14.3 \%) \\
\end{array}$ & $\begin{array}{c}1 \\
(10 \%)\end{array}$ & $\begin{array}{c}1 \\
(3.8 \%)\end{array}$ & $\begin{array}{c}1 \\
(6.7 \%)\end{array}$ & $\begin{array}{c}1 \\
(16.7 \%)\end{array}$ \\
\hline $\begin{array}{c}\text { Chr } 21 \\
(n=8)\end{array}$ & $\begin{array}{c}1 \\
(7.1 \%) \\
\end{array}$ & $\begin{array}{c}0 \\
(0 \%) \\
\end{array}$ & $\begin{array}{c}4 \\
(15.4 \%) \\
\end{array}$ & $\begin{array}{c}2 \\
(13.3 \%) \\
\end{array}$ & $\begin{array}{c}1 \\
(16.7 \%) \\
\end{array}$ \\
\hline $\begin{array}{l}\text { Chr X0 } \\
(n=2)\end{array}$ & $\begin{array}{c}0 \\
(0 \%) \\
\end{array}$ & $\begin{array}{c}0 \\
(0 \%) \\
\end{array}$ & $\begin{array}{c}2 \\
(7.7 \%) \\
\end{array}$ & $\begin{array}{c}0 \\
(0 \%) \\
\end{array}$ & $\begin{array}{c}0 \\
(0 \%) \\
\end{array}$ \\
\hline $\begin{array}{c}\text { Chr XXY } \\
(n=18)\end{array}$ & $\begin{array}{c}4 \\
(28.6 \%) \\
\end{array}$ & $\begin{array}{c}2 \\
(20 \%) \\
\end{array}$ & $\begin{array}{c}11 \\
(42.3 \%) \\
\end{array}$ & $\begin{array}{c}1 \\
(6.7 \%) \\
\end{array}$ & $\begin{array}{c}0 \\
(0 \%) \\
\end{array}$ \\
\hline $\begin{array}{c}\text { Chr YO } \\
(n=4)\end{array}$ & $\begin{array}{c}2 \\
(14.3 \%)\end{array}$ & $\begin{array}{c}0 \\
(0 \%)\end{array}$ & $\begin{array}{c}0 \\
(0 \%)\end{array}$ & $\begin{array}{c}2 \\
(13.3 \%)\end{array}$ & $\begin{array}{c}0 \\
(0 \%)\end{array}$ \\
\hline $\begin{array}{l}\text { Chr } 14 \\
(n=2)\end{array}$ & $\begin{array}{c}0 \\
(0 \%) \\
\end{array}$ & $\begin{array}{c}1 \\
(10 \%) \\
\end{array}$ & $\begin{array}{c}1 \\
(3.8 \%) \\
\end{array}$ & $\begin{array}{c}0 \\
(0 \%) \\
\end{array}$ & $\begin{array}{c}0 \\
(0 \%) \\
\end{array}$ \\
\hline $\begin{array}{l}\text { Chr } 15 \\
(n=5)\end{array}$ & $\begin{array}{c}1 \\
(7.1 \%) \\
\end{array}$ & $\begin{array}{c}1 \\
(10 \%) \\
\end{array}$ & $\begin{array}{c}2 \\
(7.7 \%) \\
\end{array}$ & $\begin{array}{c}1 \\
(6.7 \%) \\
\end{array}$ & $\begin{array}{c}0 \\
(0 \%) \\
\end{array}$ \\
\hline $\begin{array}{c}\text { Chr } 16 \\
(n=3)\end{array}$ & $\begin{array}{c}1 \\
(7.1 \%) \\
\end{array}$ & $\begin{array}{c}0 \\
(0 \%) \\
\end{array}$ & $\begin{array}{c}0 \\
(0 \%) \\
\end{array}$ & $\begin{array}{c}1 \\
(6.7 \%) \\
\end{array}$ & $\begin{array}{c}1 \\
(16.7 \%) \\
\end{array}$ \\
\hline $\begin{array}{c}\text { Chr } 22 \\
(n=3)\end{array}$ & $\begin{array}{c}0 \\
(0 \%) \\
\end{array}$ & $\begin{array}{c}1 \\
(10 \%) \\
\end{array}$ & $\begin{array}{c}0 \\
(0 \%) \\
\end{array}$ & $\begin{array}{c}1 \\
(6.7 \%) \\
\end{array}$ & $\begin{array}{c}1 \\
(16.7 \%) \\
\end{array}$ \\
\hline $\begin{array}{c}\text { Chr Others } \\
(n=20)\end{array}$ & $\begin{array}{c}3 \\
(21.5 \%)\end{array}$ & $\begin{array}{c}4 \\
(40 \%)\end{array}$ & $\begin{array}{c}5 \\
(19.3 \%)\end{array}$ & $\begin{array}{c}6 \\
(40 \%)\end{array}$ & $\begin{array}{c}2 \\
(33.3 \%)\end{array}$ \\
\hline
\end{tabular}

*Mosaicism with $\geq 60 \%$ aneuploid cells

Note: We did not have mosaics for chromosome 13

In addition, our data showed that sex chromosome abnormality is the most frequent alteration in mosaic form assessed by niPGT-A (Table 2). The chromosomal pattern of Klinefelter syndrom (XXY, 18 cases; 18/71=25\%) had the highest incidence. This should not be seen as a surprise once Klinefelter syndrom is the most frequent chromosome disorder in males (1:650 newborn males). Furthermore, our data report an incidence of approximately $32 \%$ of chromosomal mosaicism in human blastocyst established by niPGT-A using the NGS platform and the cutoff adopted by the software from Yikon Genomics. The high degree $(\geq 60 \%)$ of mosaicism in all the embryos analyzed could be hypothetically linked to niPGT-A sensitivity in detecting the self-correction phenomenon of chromosomal abnormalities in the ICM.

Finally, euploidy levels had a negative correlation with increasing age and aneuploidy levels had a positive correlation with it. This is the first report in the literature to relate chromosomal ploidy in blastocysts using niPGT-A versus increasing patient age. Thereby, a careful interpretation of the phenomenon of mosaicism established by ni-PGT-A should be a priority to avoid the discard of potentially normal embryos.

\section{CONFLICT OF INTEREST}

The authors have no conflict of interest to declare.

\section{Corresponding Author:}

José Gonçalves Franco Junior

Centre for Human Reproduction Prof Franco Jr

Ribeirão Preto/SP, Brazil.

Email: crh@crh.com.br

\section{REFERENCES}

Bolton H, Graham SJL, Van der Aa N, Kumar P, Theunis K, Fernandez Gallardo E, Voet T, Zernicka-Goetz M. Mouse model of chromosome mosaicism reveals lineage-specific depletion of aneuploid cells and normal developmental potential. Nat Commun. 2016;7:11165.

PMID: 27021558 DOI: $10.1038 /$ ncomms11165

Chuang T-H, Hsieh J-Y, Lee M-J, Lai H-H, Hsieh C-L, Wang $\mathrm{H}-\mathrm{L}$, Chang $\mathrm{Y}-\mathrm{J}$, Chen S-U. Concordance between different trophectoderm biopsy sites and the inner cell mass of chromosomal composition measured with a next-generation sequencing platform. Mol Hum Reprod. 2018;24:593-601. PMID: 30371814 DOI: $10.1093 / \mathrm{molehr} /$ gay043

Fang R, Yang W, Zhao X, Xiong F, Guo C, Xiao J, Chen L, Song $\mathrm{X}$, Wang $\mathrm{H}$, Chen $\mathrm{J}$ et al. Chromosome screening using culture medium of embryos fertilised in vitro: A pilot clinical study. J Transl Med. 2019;17:1-8.

PMID: 30849973 DOI: 10.1186/s12967-019-1827-1

Fragouli E, Alfarawati S, Spath K, Babariya D, Tarozzi N, Borini A. Analysis of implantation and ongoing pregnancy rates following the transfer of mosaic diploid-aneuploid blastocysts. Hum Genet 2017;108:62-71.

PMID: 28393271 DOI: $10.1007 /$ s00439-017-1797-4

Gleicher N, Kushnir VA, Barad DH. How PGS/PGT-A laboratories succeeded in losing all credibility. Reprod Biomed Online. 2018;37:242-5.

PMID: 30075841 DOI: $10.1016 /$ j. rbmo.2018.06.019 
Gleicher N, Albertini DF, Barad DH, Homer D, Murtinger M, Patrizio P, Orvieto R, Takahashi S, Weghofer A, Ziebe S, Noyes N. The 2019 PGDIS position statement on transfer of mosaic embryos within a contexto of new information on PGT-A. Reprod Biol Endocrinol 2020;18:57.

PMID: 32471441 DOI: 10.1186/s12958-020-00616-w

Greco E, Minasi MG. Healthy babies after intrauterine transfer of mosaic aneuploid blastocysts. N Engl J Med 2015;373:2089-90.

PMID: 26581010 DOI: $10.1056 /$ NEJMc1500421

Hardy K. Apoptosis in the human embryo. Rev of Reprod 1999;4:125-134

PMID: 12606492 DOI: 10.1095/biolreprod.102.010090

Homer HA. Preimplantation genetic testing for aneuploidy (PGT-A): The biology, the technology and the clinical outcomes. Aust N Z J Obstet Gynaecol. 2019;59:317-24.

PMID: 30811595 DOI: 10.1111/ajo.12960

Huang J, Yan L, Lu S, Zhao N, Qiao J. Re-analysis of aneuploidy blastocysts with an inner cell mass and different regional trophectoderm cells. J Assist Reprod Genet 2017;34:487-493.

PMID: 28188593 DOI: $10.1007 /$ s10815-017-0875-9

Kushnir VA, Darmon SK, Barad DH, Gleicher N. Degree of mosaicism in trophectoderm does not predict pregnancy potential: a corrected analysis of pregnancy outcomes following transfer of mosaic embryos. Reprod Biol Endocrinol. 2018;16:6.

PMID: 29373974 DOI: 10.1186/s12958-018-0322-5

Lawrenz B, El KI, Liñán A, Bayram A, Arnanz A, Chopra $\mathrm{R}$, De MN, Fatemi HM. The clinicians dilemma with mosaicism an insight from inner cell mass biopsies. Hum Reprod 2019;34: 998-1010.

PMID: 31114858 DOI: 10.1093/humrep/dez055

Munné S, Blazek J, Large $M$, Martinez-Ortiz PA, Nisson $\mathrm{H}$, Liu E, Tarozzi N, Borini A, Becker A, Zhang J, Maxwell S, Grifo J, Babariya D, Wells D, Fragouli E. Detailed investigation into the cytogenetic constitution and pregnancy outcome of replacing mosaic blastocysts detected with the use of high-resolution next-generation sequencing. Fertil Steril. 2017a;108:62-71.

PMID: 28579407 DOI: 10.1016/j. fertnstert.2017.05.002

Munné S, Wells D. Detection of mosaicism at blastocyst stage with the use of high-resolution next-generation sequencing. Fertil Steril 2017b;107:1085-91.

PMID: 28390692 DOI: 10.1016/j.fertnstert.2017.03.024

Munné S, Kaplan B, Frattarelli JL, Child T, Nakhuda G, Shamma NF, Silverberg $K$, Kalista $T$, Handyside $A H$, Katz-Jaffe M, Wells D, Gordon T, Stock-Myer S, Willman S. Preimplantation genetic testing for aneuploidy versus morphology as selection criteria for single frozen-thawed embryo transfer in good-prognosis patients: a multicenter randomized clinical trial. Fertil Steril. 2019;112:1071-9 PMID: 31551155 DOI: 10.1016/j.fertnstert.2019.07.1346

Olcha M, Elzaky M, Jaremko M, John Z, Hensinger B, Lu S. A review of 1,504 autologous embryos evaluated using a non-invasive platform for preimplantation genetic testing for aneuploidy at a private clinic. Hum Reprod 2020;35:i373
Orvieto R. Preimplantation genetic screening- the required RCT that has not yet been carried out. Reprod Biol Endocrinol. 2016;14:35.

PMID: 27342051 DOI:10.1186/s12958-016-0171-z

Orvieto R, Shuly Y, Brengauz M, Feldman B. Should preimplantation genetic screening be implemented to routine clinical practice? Gynecol Endocrinol 2016; 32:506-8.

PMID: 26872945 DOI: 10.3109/09513590.2016.1142962

Popovic M, Dheedene A, Christodoulou C, Taelman J, Dhaenens L, Van NF, Deforce D, Van den AE, De SP, Menten $B$. Chromosomal mosaicism in human blastocysts: the ultimate challenge of preimplantation genetic testing? Hum Reprod 2018; 33:1342-54.

PMID: $29796631 \quad$ DOI: 10.1093/humrep/dey106

Popovic M, Dhaenens L, Boel A, Menten B, Heindryckx B. Chromosomal mosaicism in human blastocysts: the ultimate diagnostic dilemma. Hum Reprod Update. 2020; 26: 313-34. PMID: 32141501 DOI: 10.1093/humupd/dmz050

Rubio C, Rienzi L, Navarro-Sánchez L, Cimadomo D, García-Pascual CM, Albricci L, Soscia D, Valbuena D, Capalbo A, Ubaldi F, Simón C. Embryonic cell-free DNA versus trophectoderm biopsy for aneuploidy testing: concordance rate and clinical implications. Fertil Steril. 2019;112:510-9.

PMID: 31200971 DOI: 10.1016/j.fertnstert.2019.04.038

Spinella F, Fiorentino F, Biricik A, Bono S, Ruberti A, Cotroneo E, Baldi M, Cursio E, Minasi MG, Greco E. Extent of chromosomal mosaicism influences the clinical outcome of in vitro fertilization treatments. Fertil Steril. 2018;109:77-83. PMID: 29191449 DOI: 10.1016/j. fertnstert.2017.09.025

Taylor TH, Gitlin SA, Patrick JL, Crain JL, Wilson JM, Griffin DK. The origin, mechanisms, incidence and clinical consequences of chromosomal mosaicism in humans. Hum Reprod Update 2014;20:571-81.

PMID: 24667481 DOI: 10.1093/humupd/dmu016

Tsuiko O, Zhigalina DI, Jatsenko T, Skryabin NA, Kanbekova OR, Artyukhova VG, Svetlakov AV, Teearu K, Trosin A, Salumets A. Karyotype of the blastocoel fluid demonstrates low concordance with both trophectoderm and inner cell mass. Fertil Steril 2018;109:1127-34.

PMID: 29935648 DOI: 10.1016/j.fertnstert.2018.02.008

Victor AR, Tyndall JC, Brake AJ, Lepkowsky LT, Murphy AE, Griffin. DK, Mccoy RC, Barnes FL, Zouves CG, Viotti M. One hundred mosaic embryos transferred prospectively in a single clinic: exploring when and why they result in healthy pregnancies. Fertil Steril 2019a;111:280-93.

PMID: 30691630 DOI: 10.1016/j.fertnstert.2018.10.019

Victor AR, Griffin DK, Brake AJ, Tyndall JC, Murphy AE, Lepkowsky LT, Lal A, Zouves CG, Barnes FL, McCoy RC, Viotti M. Assessment of aneuploidy concordance between clinical trophectoderm biopsy and blastocyst. Hum Reprod. 2019b;34:18192.

PMID: 30418565 DOI: 10.1093/humrep/dey327

Xu J, Fang $R$, Chen $L$, Chen $D$, Xiao JP, Yang W, Wang $H$, Song X, Ma T, Bo S, Shi C, Ren J, L, Cai LY, Yao B, Xie XS, Lu $S$. Noninvasive chromosome screening of human embryos by genome sequencing of embryo culture medium for in vitro fertilization. Proc Natl Acad Sci U S A. 2016;113:11907-12. PMID: 2768876 DOI: 10.1073/pnas.1613294113 